\title{
Pattern of Thyroid Lesions in Western Region of Saudi Arabia: A Retrospective Analysis and Literature Review
}

\author{
Muhammad I. Saeed a, b, h, Amal Ali Hassan c, d, Muhammad Ejaz Buttc ${ }^{\mathrm{c}}$, Khalid Ali Baniyaseen ${ }^{\mathrm{c}}$, \\ Muhammad I. Siddiquie, Neda M. Bogarif ${ }^{\mathrm{f}}$, Faisal A. Al-Allaff, $\mathrm{g}$, \\ Mohiuddin M. Taherf, $\mathrm{g}, \mathrm{h}$
}

\begin{abstract}
Background: Ultrasonography (US) is being recognized as a traditional way of the diagnosis of various thyroid disorders, and this will help in detecting the thyroid tumors in early stage. Thyroid nodules are common and usually benign; steps to diagnose malignancy should include a careful clinical evaluation, laboratory tests, a thyroid US exam and a fine-needle aspiration (FNA) biopsy.
\end{abstract}

Methods: A total of 173 registered cases were used for analysis in this study. Diagnosis was made following US-guided FNA cytology (FNAC) and histopathological diagnosis; clinicopathological and demographic data of all such patients were obtained and analyzed for the present study. For statistical analysis, Statistical Package of Social Sciences v.22 (SPSS) was used.

Results: In the current study, $87.3 \%$ of patients were female, and $12.7 \%$ were male. The mean age of the patients was 43.35 years, $86.4 \%$ were Saudi nationals and there was no significant difference between age groups. Overall, the distribution of lesions in all age groups was $41.6 \%$ in the right lobe, $9.3 \%$ lesions were adenomatous, $71.1 \%$ were colloid, and $10.4 \%$ were lymphocytic. The final diagnosis of thyroid lesions was confirmed after histopathological examinations. Out of 173 cases, $12.6 \%$ (20 cases) of male patients and $87.4 \%$

Manuscript submitted October 5, 2017, accepted October 23, 2017

${ }^{\text {aD }}$ epartment of Radiology, Al-Noor Specialist Hospital, Mecca, Saudi Arabia bepartment of Radiology, Umm Al-Qura University, Mecca, Saudi Arabia 'Division of Histopathology, Al-Noor Specialist Hospital, Mecca, Saudi Arabia

${ }^{\mathrm{d}}$ Faculty of Medicine, Department of Pathology, Al Azhar University, Cairo, Egypt

${ }^{e}$ Community Medicine and Public Health, Faculty of Medicine, Umm Al-Qura University, Mecca, Saudi Arabia

fDepartment of Medical Genetics, Faculty of Medicine, Umm Al-Qura University, Mecca, Saudi Arabia

${ }^{g}$ Science and Technology Unit, Faculty of Medicine, Umm Al-Qura University, Mecca, Saudi Arabia

${ }^{\text {hC}}$ Corresponding Author: Muhammad Saeed, Department of Radiology, AlNoor Specialist Hospital, Mecca, Saudi Arabia. Email: msaeed 93@yahoo. com; Mohiuddin M. Taher, Department of Medical Genetics, Faculty of Medicine, Umm Al-Qura University, Mecca, Saudi Arabia.

Email: TMMohiuddin@uqu.edu.sa

doi: https://doi.org/10.14740/jocmr3202w
(139 cases) of female patients had benign lesions, respectively. Only one male case was malignant, and seven cases were malignant in female group. Eighty percent of males and $77.7 \%$ females have colloid nodules, and $15 \%$ of males and $9.3 \%$ of females have adenomatous nodules. Four cases were non-diagnostic, one case was atypia in females, and one case was suspicious of malignancy in a male.

Conclusions: Most thyroid lesions in this study population were benign, while papillary carcinoma was the most common malignancy encountered. There was a marked female predominance in all types of thyroid diseases. The most common age group affected is $30-39$ years. In Saudi Arabia, growing prevalence of thyroid cancer may be due to the increased screening using sensitive imaging in clinical practice, and ultrasonography is the most accurate and cost-effective method for detecting thyroid lesions.

Keywords: Thyroid nodules; Goiter; Fine-needle aspiration; Ultrasound; Saudi Arabia

\section{Introduction}

The normal function of thyroid gland is essential to maintain the routine physiological activities of most organs in the human body [1]. Thyroid enlargement has been a common problem and frequently referred to the ultrasound (US)-guided radiological examinations in general clinical practice [2]. Thyroid is an endocrine gland, and its involvement has diverse functions and concerns; the major concern with thyroid lesion is the possibility of malignancy and other minor concerns are related to cosmetics and appearances. Thyroid lesions are not only a sign of the expression of a single disease but are the clinical manifestation of a wide range of different diseases [3]. Goitrous thyroid lesion is postulated as a precursor lesion to thyroid carcinoma, because in many parts of the world, endemic goiter is a major concern [4]. It is also well understood that the occurrence of thyroid lesions will increase with iodine deficiency [5]. Other common complications of thyroid are Graves' disease, Hashimoto's thyroiditis, adenoma, thyroid carcinoma, hypothyroidism, and hyperthyroidism, which are the prevalent types of thyroid disorders [6,7]. Several previous studies have reported that the prevalence of goiter varies according to the geographical region, age, and sex [4, 6-8]. The incidence of 
thyroid lesion increases with age, after radiation exposure, and women are 10 times more likely than men to have thyroid problems. According to the American Association of Clinical Endocrinologists (AACE), about 3 million people, or $4.78 \%$ of the population in USA, have undiagnosed thyroid dysfunction and according to American Thyroid Association (ATA), one in eight women will develop thyroid problems during her life time $[9,10]$.

Based on the clinical examination and non-invasive investigations, the thyroid lesions were classified into the solitary nodule, multinodular, and diffuse goiter $[11,12]$. Different reports have shown varied prevalence of thyroid lesions. In one study, palpable nodules were identified in $21 \%$ cases [13], one study suggested a prevalence of $2-6 \%$ with palpation and $19-35 \%$ with ultrasound [14], and another report showed that about $12 \%$ of the cases have a palpable goiter [15]. Subsequently, characterization of the goiters based on intraoperative findings, immune-histopathological examination, and molecular genetic testing reveals malignant changes; as such, almost it is impossible to discover the thyroid malignancies preoperatively. Thyroid cancer accounts for only $1 \%$ of all malignancies [12, 16, 17]; however, thyroid cancer accounts for $87 \%$ of all endocrine gland tumors [18]. Among the thyroid malignancies, papillary thyroid carcinoma (PTC) is the most common type which accounts for $85 \%$ of thyroid malignancies [19]. Increased incidence of thyroid cancer has been reported in the last 30 years; however, it is considered as a rare disease $[12,19]$.

Thyroid gland disorders are the most common endocrine abnormalities in Kingdom of Saudi Arabia (KSA) as well as in the Middle East region [20-27]. In KSA, thyroid cancer accounted for about $11 \%$ of all newly diagnosed cancers in 2008 in females, and this was responsible for $6.1 \%$ of all newly diagnosed cancers in the year 2004 [25, 28]. Hussain et al [25] have reported that a total of 2,292 patients with thyroid cancer were treated at KFSH\&RC, Riyadh, Saudi Arabia, from 2000 to 2010. However, in most countries, thyroid cancer accounts for approximately $1-5 \%$ of all cancers in females [29]. This cancer was ranked the second most common cancer among females, and 13th among males in Saudi Arabia [25, 28]. Saudi Arabia is a developed country in the Middle Eastern region, so the resources in the health sector are not limited [30]. However, the lack of knowledge and cultural barriers affect health awareness of the people [31]. Neck examination by US and US-guided fine-needle aspiration cytology (FNAC) is the primary option to investigate the cases of suspicious thyroid swelling [32-34], and most of the specialist centers in the kingdom have welltrained radiologists as well as well-equipped radiology departments $[35,36]$. The present study aimed to find out the pattern of thyroid lesions by the US and histopathological examinations in the Western region of Saudi Arabia.

\section{Materials and Methods}

This study was approved by the Institutional Review Board (IRB) for bioethics committee of Al-Noor Specialist Hospital, Mecca, KSA. A total of 173 registered cases (between January
2008 and December 2011), at the Radiology Department of Al-Noor Specialist Hospital, Mecca, were used for analysis in this study. Patients presenting with thyroid swelling referred to radiology department by the outpatient and in-patient's departments of the hospital were included in this study. The diagnosis was made following the US-guided FNAC and histopathological diagnosis was confirmed using The Bethesda System for Reporting Thyroid Cytopathology (TBSRTC) in all the cases [37]. Clinicopathological and demographic data of all such patients were obtained and analyzed for the present study. For statistical analysis, Statistical Package for Social Sciences (SPSS) version 22 was used. The quantitative variables like age and the qualitative variables like histopathological diagnosis were presented.

\section{Results}

One hundred and seventy-three patients with thyroid swelling were included in the analysis of the present study. Table 1 shows the distribution of patients according to their sex and age groups in this study population. In the current study, $87.3 \%$ of patients $(\mathrm{n}=151)$ were female, and $12.7 \%$ were male $(\mathrm{n}=$ 22). The mean age of the patients was 43.35 years, and the minimum and maximum ages were 12 and 101 years, respectively. There was no significant difference between age groups $(\mathrm{P}=0.128)$. However, more patients were in age groups of 31 - 40 years $(23.1 \%)$ and $28.9 \%$ were in the age group of $41-50$ years. Fewer patients were in the age groups of less than 20 years and above 50 years, respectively. Nine females and one male were in the age group of less than 20 years, and a total of eight males and 38 females were in the age group of above 50 years. In the age groups of 21 - 30, 31 - 40, and 41 - 50 years, there were only four, three, and six male patients, respectively. Whereas, the females in these age groups were 23, 37, and 44 , respectively. More male and female patients were in the age group of 41 - 50 years. Distribution of patients according to their nationalities is shown in Table 2. Of the patients, $86.4 \%$ were Saudi nationals, around $4 \%$ were Pakistanis, and around $3.3 \%$ were Yemenis, followed by Syrians $(2.7 \%)$ and then Egyptians (2\%); rests were other nationals like Palestinians, Indonesians, Filipino, Bangladeshis, and from Myanmar. In the male category among all nationals, $86.4 \%$ were from Saudi Arabia, and in the females, $84.1 \%$ were Saudis. There were no male cases in nationals from Syria, Palestine, Egypt, Yamen, Indonesian, Philippines, Bangladesh, and Myanmar.

Distribution of thyroid lesions according to their location in different age groups and different sexes is shown in Table 3. In the age category of $<20$ years, a total of four patients had lesions on right thyroid lobe, three patients had lesions on left thyroid, and three patients on both sides. In the age category of 21 - 30 years, a total of 18 patients had lesions on right thyroid lobe, two patients had lesions on left thyroid, and seven patients on both sides. In the age category of $31-40$ years, a total of 15 patients had lesions on right thyroid lobe, 11 patients had lesions on left thyroid, and 12 patients on both sides, one patient on isthmus, and one patient had a diffuse nodule. In the age category of 41 - 50 years, a total of 18 patients had lesions 
Table 1. Distribution of Thyroid Lesions According to Gender and Age of the Patients

\begin{tabular}{llll}
\hline Age groups (years) & Male (\%) & Female (\%) & Total (\%) \\
\hline$<20$ & $1(10)$ & $9(90)$ & $10(5.8)$ \\
$21-30$ & $4(14.8)$ & $23(85.2)$ & $27(15.6)$ \\
$31-40$ & $3(7.5)$ & $37(92.5)$ & $40(23.1)$ \\
$41-50$ & $6(12)$ & $44(88)$ & $50(28.9)$ \\
$51-60$ & $4(15.4)$ & $22(84.6)$ & $26(15)$ \\
$>61$ & $4(20)$ & $16(80)$ & $20(11.6)$ \\
Total & $22(12.7)$ & $151(87.3)$ & $173(100)$ \\
\hline
\end{tabular}

Pearson Chi-square $=0.068$.

on right thyroid lobe, eight patients had lesions on left thyroid, and 22 patients on both sides, one patient on isthmus, and one patient had a lymph node only. In the age category of $51-60$ years, a total of eight patients had lesions on right thyroid lobe, six patients had lesions on left thyroid, and 12 patients on both sides. In the age category of $>60$ years, a total of nine patients had lesions on right thyroid lobe, three patients had lesions on left thyroid, and eight patients on both sides. Overall, the distributions of lesions in all age groups were $41.6 \%$ on right side, $19.1 \%$ on left side, $37 \%$ on both sides, $1.2 \%$ on isthmus, $0.6 \%$ with diffuse lesions, and $0.6 \%$ with lymph node only.

Benign nodule distribution in different age groups is
Table 2. Distribution of Patients According to Their Nationalities and Gender

\begin{tabular}{lllll}
\hline Origin of patients & Male (\%) & Female (\%) & Total & Percent \\
\hline Saudi & $19(86.36)$ & $127(84.10)$ & 146 & 84.39 \\
Syrian & 0 & $4(2.66)$ & 4 & 2.31 \\
Palestinian & 0 & $1(0.66)$ & 1 & 0.58 \\
Egyptian & 0 & $3(1.99)$ & 3 & 1.73 \\
Pakistani & $3(13.64)$ & $6(3.98)$ & 9 & 5.2 \\
\hline Yemeni & 0 & $5(3.31)$ & 5 & 2.89 \\
Indonesian & 0 & $1(0.66)$ & 1 & 0.58 \\
Bangladeshi & 0 & $1(0.66)$ & 1 & 0.58 \\
Filipino & 0 & $2(1.32)$ & 2 & 1.16 \\
Myanmar & 0 & $1(0.66)$ & 1 & 0.58 \\
Total & $22(100)$ & $151(100)$ & 173 & 100 \\
\hline
\end{tabular}

shown in Table 4 . In the age category of $<20$ years, one adenomatous lesion, seven colloid lesions, and two lymphocytic lesions were present. In the age category of 21 - 30 years, two adenomatous lesions, 15 colloid lesions, and five lymphocytic lesions were present. In the age category of 31 - 40 years, six adenomatous lesions, 30 colloid lesions, and three lymphocytic lesions were present. In the age category of 41-50 years, two adenomatous lesions, 38 colloid lesions, and five lymphocytic

Table 3. Distribution of Thyroid Lesions According to Age Groups and Location

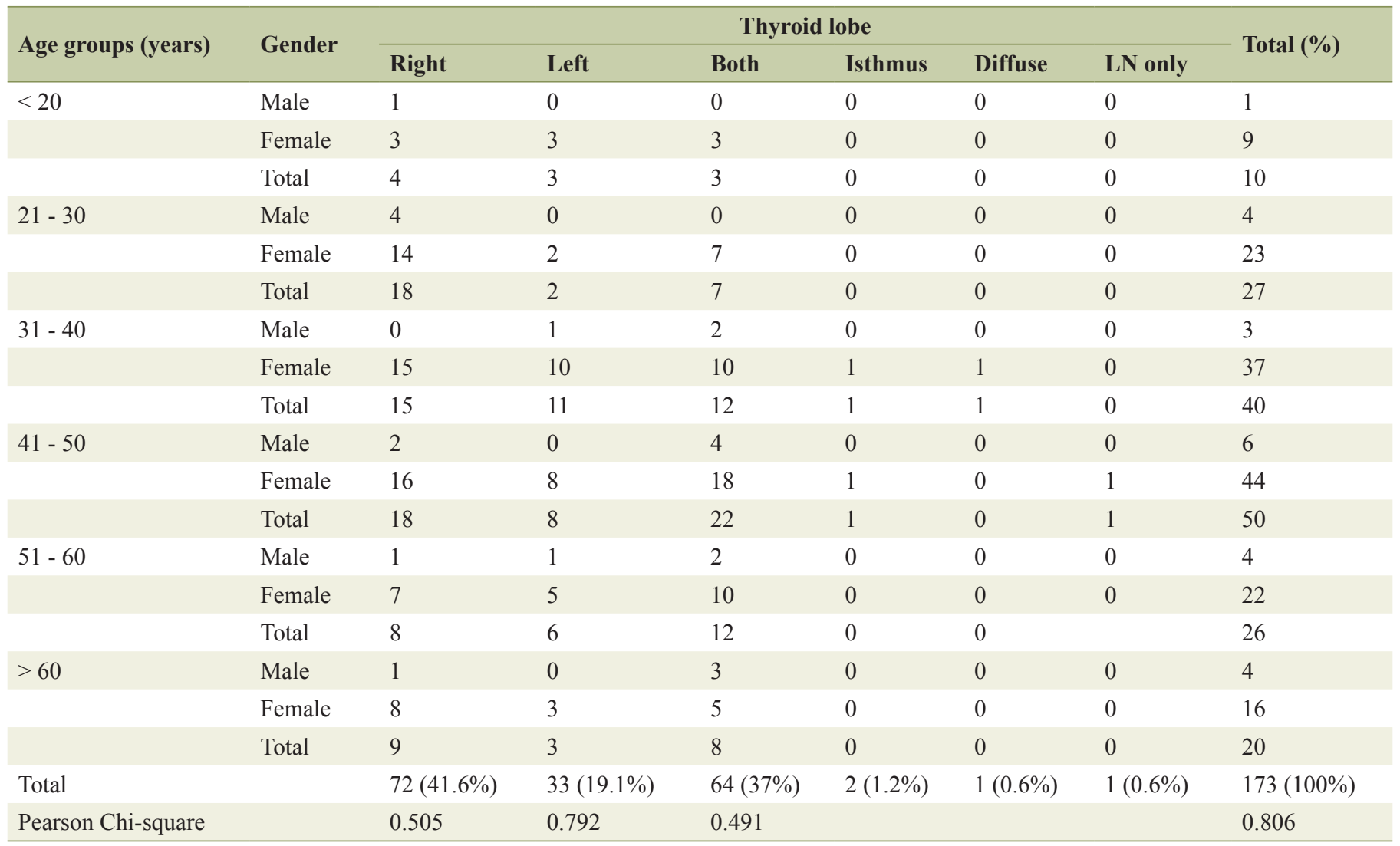


Table 4. Distribution of Benign Nodules According to Age Groups of Patients

\begin{tabular}{|c|c|c|c|c|c|c|}
\hline \multirow{2}{*}{ Age groups (years) } & \multicolumn{5}{|c|}{ Benign nodules (\%) } & \multirow{2}{*}{ Total (\%) } \\
\hline & Not benign & Adenomatous & Colloid & Lymphocytic & Others & \\
\hline$<20$ & 0 & 1 & 7 & 2 & 0 & 10 \\
\hline $31-40$ & 1 & 6 & 30 & 3 & 0 & 40 \\
\hline $41-50$ & 5 & 2 & 38 & 5 & 0 & 50 \\
\hline Total & $14(8.1)$ & $16(9.3)$ & $124(71.7)$ & $18(10.4)$ & $1(0.6)$ & $173(100)$ \\
\hline
\end{tabular}

lesions were present. In the age category of 51 - 60 years, three adenomatous lesions, 18 colloid lesions, and three lymphocytic lesions were present. In the age category of $>60$ years, two adenomatous lesions and 16 colloid lesions were present. Overall, the distributions of benign lesions in all age groups were 9.3\% adenomatous, $71.1 \%$ colloid, and 10.4\% lymphocytic, and $8.1 \%$ were not benign including malignance. In Table 5, the final diagnosis of thyroid lesions after histopathological examinations is shown. Out of the total 173 cases, the benign lesions in male category were 20 cases $(12.6 \%)$, and in female were 139 cases $(87.4 \%)$. Only one case in male was malignant, and seven cases were malignant in the female group. Eighty percent of males and $77.7 \%$ females had colloid nodules, and $15 \%$ of males and $9.3 \%$ of females had adenomatous nodules. Four cases were non-diagnostic, and one case was atypia in females, and one case was suspicious of malignancy in a male.

Final diagnosis in distribution in different age groups and sexes is shown in Table 6 . In the age category of $<20$ years, one male and nine females had benign. In age category of 21 - 30 years, two males and 20 females had benign lesions, one male and three females had malignant lesions, and one male was diagnosed with suspicious of malignancy (SOM). In age category of 31 - 40 years, three male and 36 female cases were

Table 5. Spectrum of Thyroid Diseases in Different Sexes by Final Diagnosis

\begin{tabular}{|c|c|c|c|}
\hline \multirow{2}{*}{ Thyroid lesions } & \multicolumn{2}{|c|}{ Gender (\%) } & \multirow{2}{*}{ Total (\%) } \\
\hline & Male & Female & \\
\hline Non-diagnostic & 0 & $4(2.65)$ & $4(2.31)$ \\
\hline Benign & $20(90.92)$ & $139(92.1)$ & $159(91.91)$ \\
\hline Atypia & 0 & $1(0.66)$ & $1(0.6)$ \\
\hline SOM & $1(4.54)$ & 0 & $1(0.6)$ \\
\hline Malignant & $1(4.54)$ & $7(4.64)$ & $8(4.63)$ \\
\hline Total & $22(12.72)$ & $151(87.28)$ & $173(100)$ \\
\hline Adenomatous nodules & $3(15)$ & $13(9.35)$ & $16(10.2)$ \\
\hline Colloid nodules & $16(80)$ & $108(77.7)$ & $124(77.91)$ \\
\hline Lymphocytic (Hashimoto) & $1(1)$ & $17(12.24)$ & $18(11.31)$ \\
\hline Others & 0 & $1(0.72)$ & $1(0.63)$ \\
\hline Total (benign) & $20(12.58)$ & $139(87.42)$ & $159(100)$ \\
\hline
\end{tabular}

SOM: suspicious of malignancy. benign, and one female case was malignant. In age category of 41 - 50 years, six male cases and 39 female cases were benign, two female cases were malignant, and three female cases were non-diagnostic. In age category of 51 - 60 years, four male and 21 female cases were benign, and one female case was nondiagnostic. In age category of $>60$ years, four male cases and 14 female cases were benign, one female case was malignant, and one female was with atypia.

Figure 1 shows the characteristics of thyroid lesions found by the US, such as number of nodules, size, shape, consistency

Table 6. Distribution of Thyroid Lesions According to Age Groups in Different Sexes

\begin{tabular}{|c|c|c|c|c|}
\hline \multirow{2}{*}{$\begin{array}{l}\text { Age groups } \\
\text { (years) }\end{array}$} & \multirow{2}{*}{ Diagnosis } & \multicolumn{2}{|c|}{ Gender (\%) } & \multirow{2}{*}{ Total (\%) } \\
\hline & & Male & Female & \\
\hline \multirow[t]{2}{*}{$<20$} & Benign & $1(100)$ & $9(100)$ & 10 \\
\hline & Total & $1(100)$ & $9(100)$ & 10 \\
\hline \multirow[t]{4}{*}{$21-30$} & Benign & $2(50)$ & $20(86.96)$ & 22 \\
\hline & SOM & $1(25)$ & 0 & 1 \\
\hline & Malignant & $1(25)$ & $3(13.04)$ & 4 \\
\hline & Total & $4(100)$ & $23(100)$ & 27 \\
\hline \multirow[t]{3}{*}{$31-40$} & Benign & $3(100)$ & $36(97.3)$ & 39 \\
\hline & Malignant & 0 & $1(2.7)$ & 1 \\
\hline & Total & $3(100)$ & 37 & 40 \\
\hline \multirow[t]{4}{*}{$41-50$} & Non-diagnostic & 0 & $3(6.82)$ & 3 \\
\hline & Benign & $6(100)$ & $39(88.7)$ & 45 \\
\hline & Malignant & 0 & $2(4.55)$ & 2 \\
\hline & Total & $6(100)$ & $44(100)$ & 50 \\
\hline \multirow[t]{3}{*}{$51-60$} & Non-diagnostic & 0 & $1(4.55)$ & 1 \\
\hline & Benign & $4(100)$ & $21(95.45)$ & 25 \\
\hline & Total & $4(100)$ & $22(100)$ & 26 \\
\hline \multirow[t]{4}{*}{$>60$} & Benign & $4(100)$ & 14 & 18 \\
\hline & Atypia & 0 & 1 & 1 \\
\hline & Malignant & 0 & 1 & 1 \\
\hline & Total & $4(20)$ & $16(80)$ & 20 \\
\hline Grand total & & $22(12.72)$ & $151(87.28)$ & $173(100)$ \\
\hline
\end{tabular}

SOM: suspicious of malignancy. 


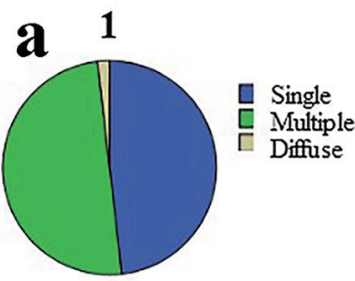

Number

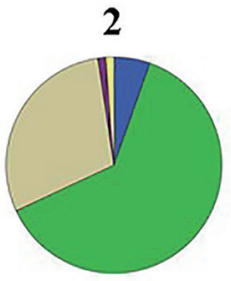

Size

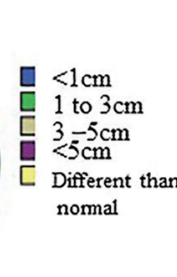

1 to $3 \mathrm{~cm}$
$\begin{gathered}3-5 \mathrm{~cm} \\ <5 \mathrm{~cm} \\ \text { Different } \\ \text { normal }\end{gathered}$

Shape

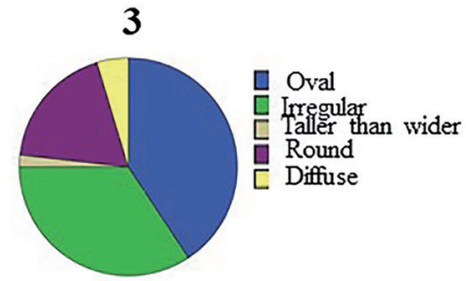

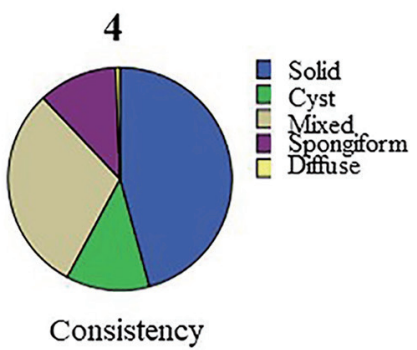
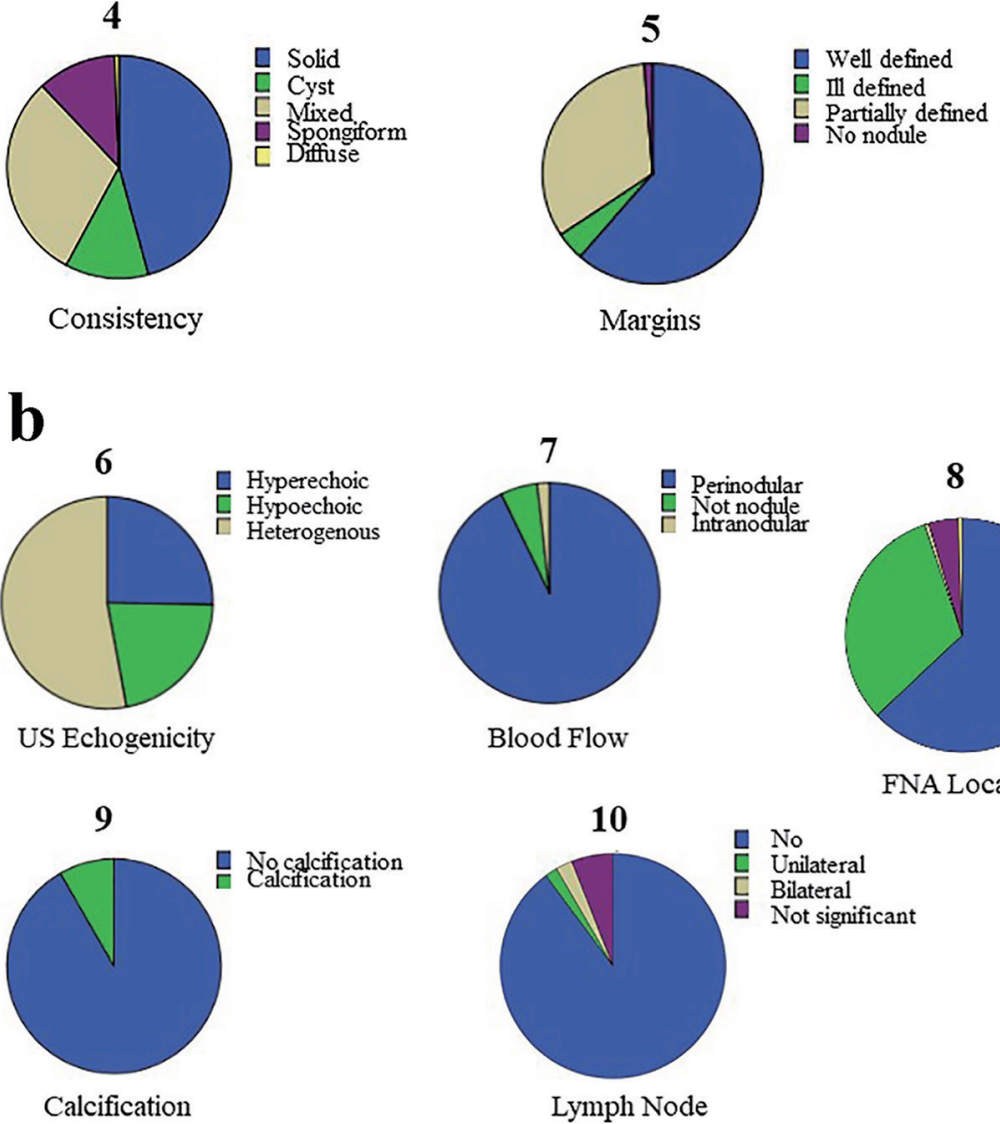

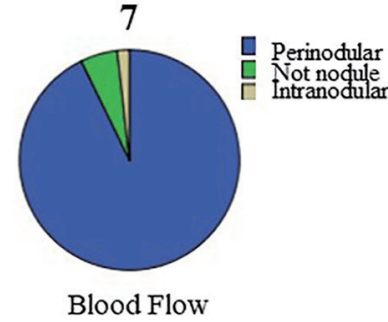

10

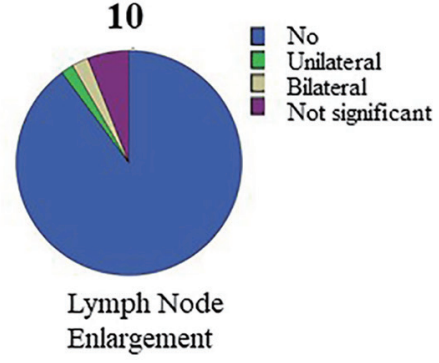

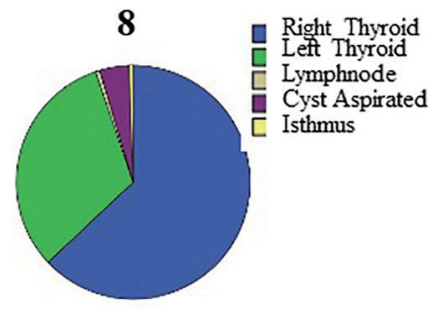

FNA Location

Figure 1. Characteristics of thyroid lesions found by ultrasonography. Panel (a) showing (1) number of nodules, (2) size of the nodules, (3) shape of the nodules, (4) consistency of the nodules, and (5) margins of the nodules. Panel (b) showing (6) US echogenicity of the nodules, (7) blood flow to the nodules, (8) site of the FNA done, (9) calcification of the nodules, and (10) lymph node enlargement in the nodules.

of the nodules, margins, US echogenicity, blood flow, FNA status, calcification and lymph node enlargement. Solitary nodules and multinodular lesions were almost equal and very few cases had diffuse nodules. In terms of nodule sizes, most of the cases had $1-3 \mathrm{~cm}$ of nodules, the second largest group had $3-5 \mathrm{~cm}$ of nodules, and very few cases had $>1 \mathrm{~cm}$, and $<$ $5 \mathrm{~cm}$ sizes of nodules. Majority of cases had oval shape of nodules, second largest group of cases had an irregular shape of nodules, and a third largest group had round shape of nodules. Most of the cases had solid nodules, second largest group had mixed nodules, and spongiform, and cystic nodule cases were in the third category. Majority of cases had lesions with welldefined shaped margins, the next group had partially defined margins, and the ill-defined margin cases were rare (Fig. 1a). Most of the thyroid lesions had heterogenic echogenicity, and hyperechoic and hypoechoic cases were almost the same. Most of the cases had peri-nodular blood flow, second largest group had no blood flow, and very few cases had intra-nodular blood flow. Majority of cases had lesions on right thyroid, and the second largest group of cases had left thyroid lesions. Most of 

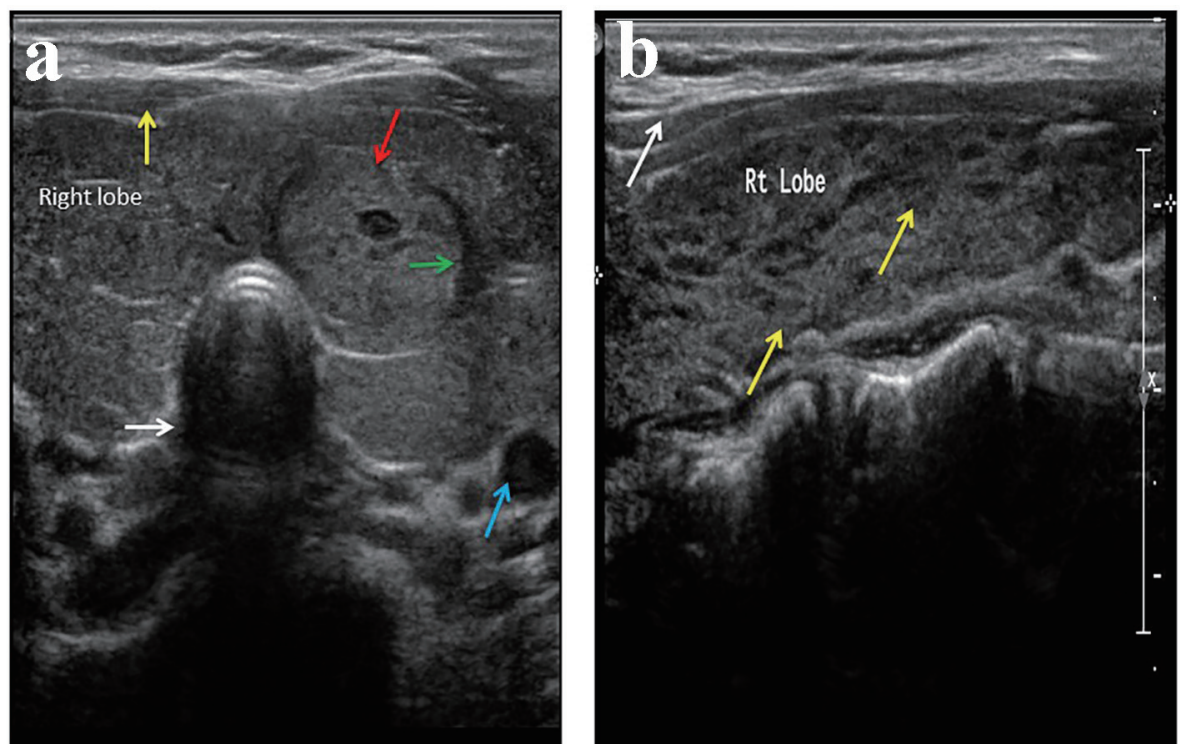

Figure 2. Ultrasound features of the various types of thyroid lesions. Panel (a) showing adenomatous thyroid lesion with arrows indicating strap muscles (yellow), margin of nodule (green), trachea (white), heterogeneous nodule (red), and internal jugular vein (blue). Panel (b) showing Hashimoto's thyroiditis (chronic lymphocytic thyroiditis) with arrows indicating multiple tiny hypoechoic nodular lesions (yellow) and strap muscles (white).

the cases had no calcification, and a small proportion of cases had calcification of nodules. No lymph node enlargement was found in most of cases (Fig. 1b).

Ultrasound features of the various types of thyroid lesions found in this study were shown in Figures 2, 3 and 4. Figure $2 \mathrm{a}$ shows a representative case of the adenomatous thyroid lesion; the left lobe of a thyroid shows solid isoechoic lesion with mildly heterogeneous internal echoes and thin peripheral halo. Figure $2 \mathrm{~b}$ shows a representative case of the Hashimoto thyroiditis; the thyroid gland shows heterogeneous echo texture with a presence of multiple hypoechoic micro-nodules (1 - 6 $\mathrm{mm}$ ) surrounded by echogenic septations. Hashimoto thyroiditis (chronic lymphocytic thyroiditis) indicates multiple tiny hypoechoic nodular lesions (yellow arrow) and strap muscles (white arrow). A representative case of the colloid lesion of the thyroid is shown in Figure 3a. Right lobe of thyroid shows a large welldefined cystic nodule with internal septations and echoes. Colloid thyroid lesion with multiple cystic lesions is indicated by a white arrow; strap muscles are shown in yellow arrows. Figure $3 \mathrm{~b}$ is a lymphoplastc thyroid lesion with the white arrow indicat-
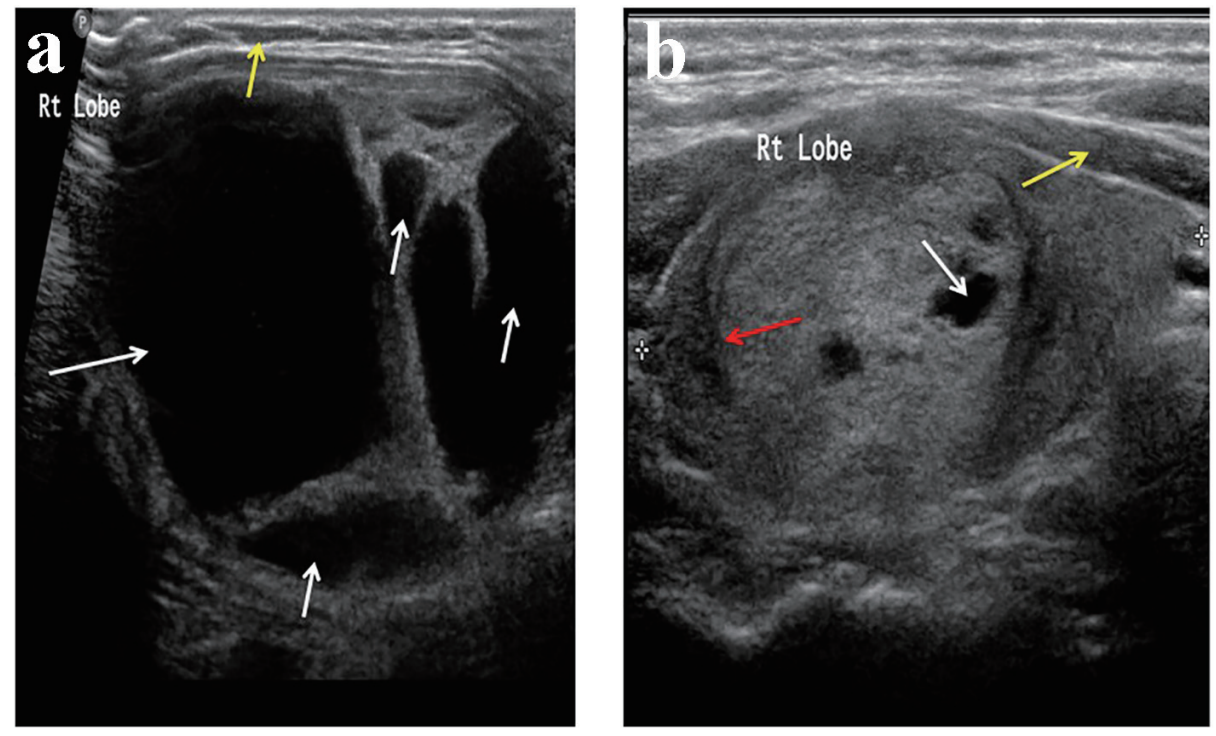

Figure 3. Ultrasound features of a colloid thyroid lesion. Panel (a) showing multiple cystic lesions (white arrows) and strap muscles (yellow). Panel (b) showing lymphoplastc thyroid lesion with arrows indicating cystic changes (white), strap muscles (yellow), and margin of nodule (red). 


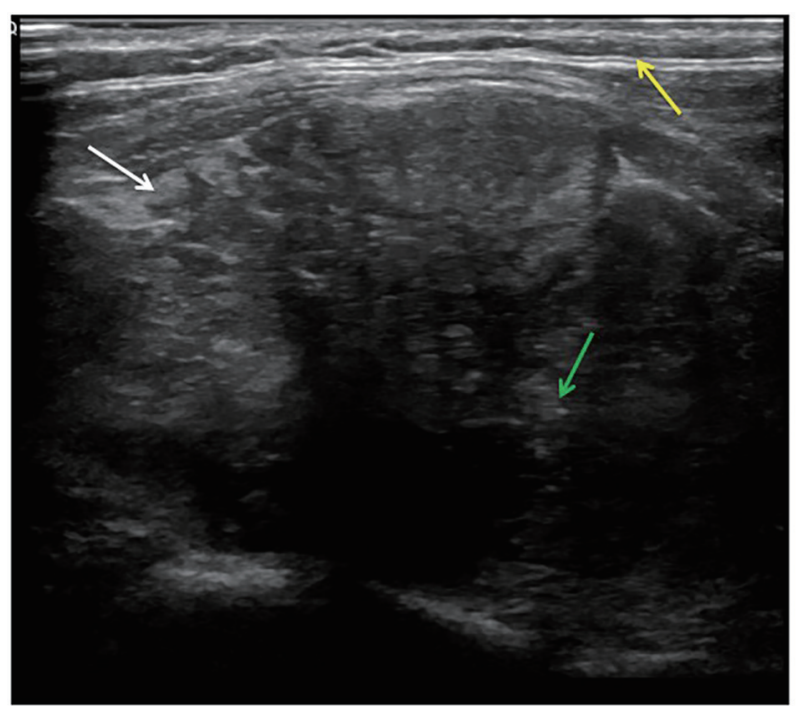

Figure 4. Ultrasound features of a malignant thyroid nodule. Malignant thyroid lesions with irregular margins are indicated by white arrow marked hypoechogenic; strap muscles and microcalcification are indicated by yellow and green arrows, respectively.

ing cystic changes, strap muscles in yellow arrows, and a margin of a nodule in red arrow. Figure 4 shows a representative case of the malignant nodule; the thyroid shows a solitary subcapsular mass with an irregular outline, demonstrating small punctate regions of echogenicity representing microcalcifications and intrinsic echo free area representing necrosis.

In Figures 5 and 6, histopathology of various thyroid lesions stained with H\&E, Papanicolaou stain, and Diff quick stain is shown from the representative cases studied in this investigation. Hashimoto thyroiditis with diffuse lymphoplasmacytic infiltration is shown in Figure 5a, b. In Figure 5a, lymphoid follicles with germinal centers are shown in yellow, normal thyroid follicular tissue present around lymphoid follicles is indicated by black arrows (Pap stain, $\times 10$ ). Figure 5 b shows the germinal centers by the green arrow, red blood cells are indicated by black arrow (H\&E stain, $\times 40)$. Figure $5 \mathrm{c}$ is a colloid goiter which shows varied sizes of thyroid follicles lined by low cuboidal epithelium indicated by the green arrow and filled by eosinophilic colloid, and the blue arrows indicate thyroid follicles (H\&E stain, $\times 20)$. In Figure 5d, FNA cell block of follicular carcinoma with tumor tissue showing several neoplastic follicles is indicated by black arrows, also indicated by yellow arrows is the blood clot surrounding the neoplastic tissue $(\mathrm{H} \& \mathrm{E}, \times 20)$. Diff quick stained slide $(\times 40)$ is shown in Figure 6a, papillae showing clusters of malignant follicular epithelial cells are indicated by red arrows. In Figure 6b, the classic pattern of PTC is depicted. Photomicrographs (Pap stain, $\times 40)$ show papillary structures consisting of many neoplastic follicular epithelial cells with intranuclear cytoplasmic pseudo-inclusions indicated by black arrows. Figure $6 \mathrm{c}$ shows H\&E stained photomicrograph of a PTC from an FNA cell block $(\times 40)$. Papillary structures consisting of many neoplastic follicular epithelial cells (green arrow) lining the papillae with a fibrovascular core are clearly visible (yellow arrow).

\section{Discussion}

Thyroid nodules are extremely common in the general population and are usually discovered during routine medical examination. Around $4-7 \%$ of the general population develop clinically palpable thyroid nodules [38]. The main cause of thyroid enlargement included simple goiter which is followed by thyroiditis. Toxic goiter and malignant goiter were observed in $7.83 \%$ and $12.65 \%$ of cases, respectively [39]. Of the simple euthyroid goitrous lesions, the most common were solitary adenoma, followed by diffuse hyperplastic goiter and multinodular goiter. But more than $90 \%$ of the detected nodules are clinically insignificant benign lesions while thyroid cancer represents only $5-25 \%[32,40]$.

In our current study, around $85 \%$ of all our patients were Saudi Arabian nationals, the mean age in our study was 43.35 years, and in a study conducted in India, the patient's mean age was $37.69 \pm 14.93$ years [34]. In another study from western Saudi Arabia, the mean age for males was $41.35 \pm 15.52$ years compared to $36.59 \pm 13.28$ years for females [27]. We found the highest incidence of thyroid swelling in the fourth decade of life, with a maximum number of patients in the age group of 41 - 50 years $(28.9 \%)$, followed by another peak in the age group of 31 - 40 years $(23.1 \%)$. In a study from the Indian region of Sikkim, Sengupta et al [39] have found more cases were in the age group of 30 - 39 years (31.32\%), and Qureshi et al also reported that the most affected age group was $31-40$ years [40].

The patterns of thyroid lesions observed in the current investigation are comparable with the available world literature. Ezzat et al [13] have reported that the prevalence of thyroid lesions was greater in women than in men. A concordance rate of $49 \%$ was noted between US and findings by palpation in their study. In our study, out of 173 total cases, $87.4 \%$ cases were females and the overall male to female ratio in our study was $1: 7$. This was hugely increased to $1: 12.3$ in the age group of 31 - 40 years old. Salama et al [41] have reported $78.9 \%$ from western region of $\mathrm{KSA}$, and in another study from Madinah, Al-Bouq et al [42] found $84.65 \%$ females with thyroid lesions. Many reports have shown this sex ratio for male to female in the range of 1:5 - 9 [39, 43-45]. In terms of characteristics of thyroid lesions, most patients have the solitary or multinodular lesions in equal numbers, followed by diffuse lesions, whereas in another study the most common was solitary lesions, followed by diffuse lesions, and multinodular lesions [39]. Another Indian study conducted by Abrari et al showed $54.7 \%$ of multinodular goiter, which agrees with our observation [46]. The nodule size in our study ranges from 1 to $3 \mathrm{~cm}$, and most of the patients had an oval or irregular shape of nodules, with well-defined margins of solid consistency. Most of the patients had heterogeneous echogenic nodules than hyper-echoic or hypo-echoic, and the lesions had peri-nodular blood flow, with no calcification, and no lymph node enlargement. Most of the FNA done was on right thyroid lobe followed by left lobe.

In our study, around $4.63 \%$ are malignant lesions, $92 \%$ are benign nodules including $78 \%$ colloid, $11.31 \%$ Hashimotos or lymphoplastic, and $10.2 \%$ adenomatous nodules. This agrees with a study from Pakistan where they have shown the largest 

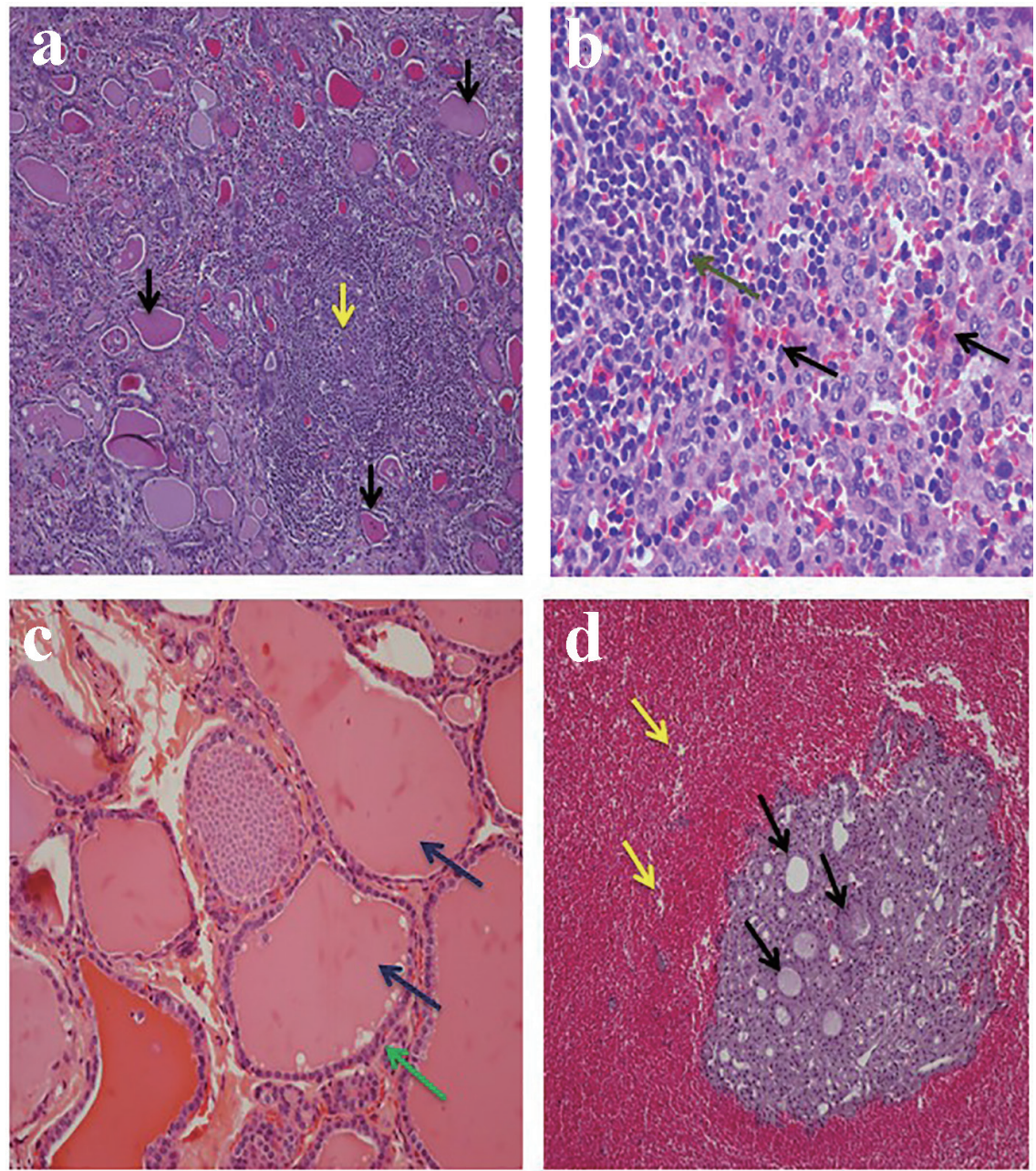

Figure 5. Histopathology of the representative cases with various thyroid lesions stained with H\&E, Papanicolaou stain, and Diff quick stain. In panel (a), Hashimoto's thyroiditis showing diffuse lymphoplasmacytic infiltration, lymphoid follicles with germinal centers (yellow), normal thyroid follicular tissue (black arrows) present around lymphoid follicles (Pap stain, $\times 10)$. Panel (b) showing germinal centers (green arrow), red blood cells are indicated by black arrows (H\&E stain, $\times 40$ ). Panel (c) is a colloid goiter showing varied sizes of thyroid follicles lined by low cuboidal epithelium (green arrow) and filled by eosinophilic colloid. Blue arrows indicate thyroid follicles (H\&E stain, $\times 20)$. Panel (d) is an FNA cell block of follicular carcinoma - tumor tissue showing several neoplastic follicles (black arrows). Blood clot surrounds the neoplastic tissue (yellow arrows, H\&E $\times 20$ ).
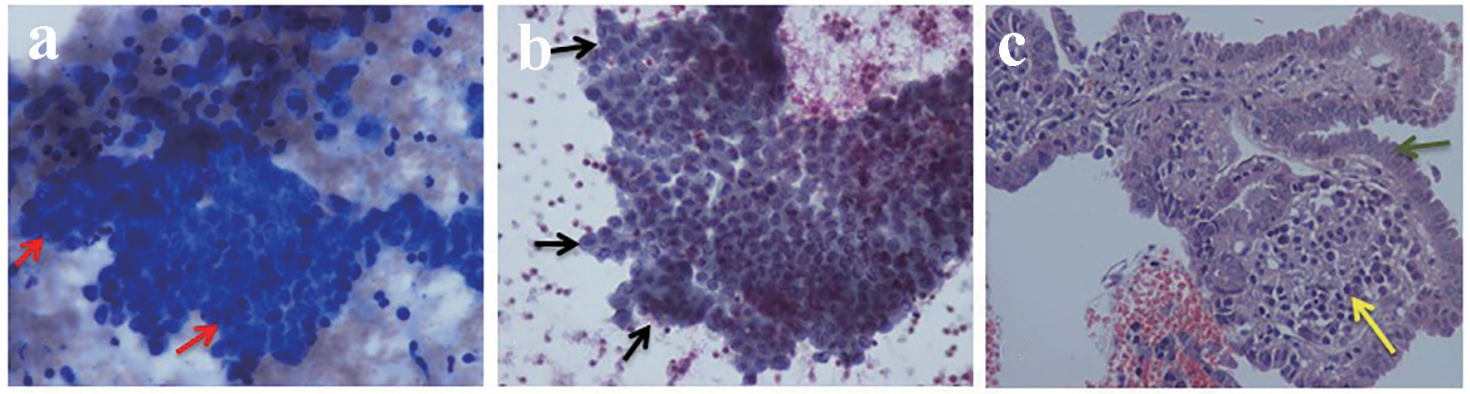

Figure 6. Histopathology of the representative cases with neoplastic thyroid lesions stained with H\&E, Papanicolaou stain, and Diff quick stain. Panel (a) showing a Diff quick stained slide $(\times 40)$, papillae showing clusters of malignant follicular epithelial cells (red arrows). In panel (b), a classic pattern of papillary carcinoma is presented. Photomicrographs (Pap stain, $\times 40$ ) show papillary structures consisting of many neoplastic follicular epithelial cells with intranuclear cytoplasmic pseudo-inclusions indicated by black arrows. Panel (c), FNA cell block, showing papillary carcinoma (H\&E, $\times 40)$. Papillary structures consisting of many neoplastic follicular epithelial cells (green arrow) lining the papillae with fibrovascular core (yellow arrow). 
number of patients had benign lesions [47], and another study from India has reported $12.65 \%$ of malignancy, with papillary carcinoma being the most common variant. Some other studies $[26,39,40]$ have reported less cases of Hashimoto thyroiditis $(2.6 \%, 3.01 \%$ and $3.8 \%)$ compared to our finding $(11.31 \%)$. Hashimoto thyroiditis is an autoimmune disease associated with gradual infiltration of the thyroid by $\mathrm{T}$ and $\mathrm{B}$ lymphocytes causing the destruction follicles, also fibrosis with the reduction in thyroid function and hypothyroidism [48]. Hashimoto thyroiditis is not only the most common form of thyroiditis but also the most common thyroid disorder [49]. The disease, which is also known as chronic lymphocytic thyroiditis or autoimmune thyroiditis, affects 14 million people in the United States alone [50]. It is an autoimmune disorder, which means it occurs when immune cells attack healthy tissue instead of protecting it. Autoimmune diseases affect women more than men, and women are seven times more likely to have Hashimoto thyroiditis [51]. In the present study, around $78 \%$ cases had colloid nodules; Albasri et al have reported in the Madinah region also colloid goiter was the most common lesion [26]. Colloid nodules are the most commonly encountered solitary thyroid lesions, and a US examination may reveal numerous other small nodules as part of a multi-nodular gland. These nodules are formed mainly of a collagenous material interspersed with benign thyroid cells with little or no malignant potential. Follicular adenomas are benign tumors that grow in a glandular of follicular pattern, and tend to develop slowly with pseudo-capsule of compressed normal thyroid tissue [52]. In another study from Mexico, the findings were colloid goiter (47.2\%), follicular adenomas (23.5\%), Hashimoto thyroiditis $(20.5 \%)$, and papillary carcinomas $(5.9 \%)$, and we have also found around $5 \%$ malignant cases, but our data for colloid, Hashimoto and adenomatous lesions are in contrary to this report [45].

Many centers have adopted the method of USG for the diagnosis of various thyroid problems, and this will help in detecting the thyroid tumors in an early stage. These diagnostic dilemmas have important consequences for the management and prognosis of these patients. Martin and Ellis in 1930 [53] were the first to report the diagnosis of thyroid lesions using aspiration cytology (FNAC). Improvement in the detection of thyroid lesions became easy by extensive use of US of thyroid; the US detects lesions in up to $67 \%$ of the population [13]. Thyroid lesions are common and usually benign, the risk of malignancy varies from $5 \%$ to $10 \%$, and diagnosis of thyroid malignancy should include a careful clinical examination, laboratory tests, a thyroid US exam and an FNA biopsy (FNAB) followed by immunochemistry [29, 32, 33]. Thyroid FNAB is the most precise test for determining malignancy, and is an integral part of current thyroid nodule evaluation. Although many reports have demonstrated malignant US features require US-guided FNAB for further confirmation, it is hard to decide which lesions should undergo FNAB because the same thyroid lesions may be classified in different ways with different guidelines [30,31]. The ATA guidelines recommend FNA examination of lesion larger than $1-1.5 \mathrm{~cm}$ with suspicious US pattern or of the largest nodule if US features are not suspicious [54]. The AACE recommendation for evaluating patients with multiple lesions differ because they consider the US patterns the primary indication for evaluating nodules by FNA irrespective of their size [55].

Sengupta et al [39] have reported around $12.65 \%$ malignant cases which are twice than we observed in Saudi Arabia. In the study conducted by Handa et al, the incidence of malignant tumors was $3.9 \%$, of which papillary carcinoma was the most common [34]. In our study, we found 5\% malignant cases with papillary carcinoma as the common one. Several studies have shown that immunohistochemistry may provide additional support in the evaluation and diagnosis of thyroid tumors [56, 57]. Many authors have explored immunohistochemistry as a complement to the morphological criteria for the diagnosis of well-differentiated thyroid tumors. Hector Battifora mesothelial-1 (HBME-1), galectin-3, and cytokeratin-19 (CK19) are the most frequently explored antibodies in thyroid pathology $[56,57]$. Thyroid cancer is a rare disease which accounts for only $1 \%$ of all malignancies in developed countries [12]. PTC is the most common (85\%) malignant disorder of the endocrine system, and it is characterized by a distinctive set of nuclear features [12].

In conclusion, most thyroid lesions in this study population were benign presenting as simple euthyroid goiter. Autoimmune thyroiditis was the most common form of inflammation of the thyroid gland while papillary carcinoma was the most common malignancy encountered. There was, as expected, marked female predominance in all types of thyroid diseases and this was mostly marked in toxic goiters. The commonest age group affected is 30 - 39 years, while the extremes of age below 10 and above 70 years were rarely involved. In Saudi Arabia growing prevalence of thyroid cancer may be due to the increased screening using sensitive imaging in clinical practice and diagnosis, and not only an increase in the true occurrence of thyroid cancer [8,20,21, 25-27], but also incidental thyroid nodules are being discovered with increasing frequency. Ultrasound is the most accurate and cost-effective method for detecting thyroid lesions. Risk factors, such as female gender, and age were highlighted in the studies here, emphasizing the importance of public health programs that are aimed at tackling such determinants. Large scale studies are needed to follow the prognosis and determinants of this condition in the Arab world. This study recommended early detection and prevention of disease at the primary level by educating the population should be practiced.

\section{Acknowledgments}

The authors would like to thank Dr. Hani S. Faidah, the Director of Blood bank and laboratory medicine department at Al-Noor Specialist Hospital, the staff of Science and Technology Unit (STU) and Deanship of Scientific Research (DSR) at Umm Al-Qura University, Mecca, for their continuous support.

\section{Author Contributions}

Concept and design: MIS, AAH, and MMT. Supervision: MEB, FAA and NMB. Resources and materials: MIS, AAH 
and KABY. Data collection and analysis: MIS, MISI, and MEB. Interpretation: MIS, AAH, KABY and MEB. Literature search: MIS and MMT. Writing manuscript: MIS, MMT, MEB and $\mathrm{AAH}$.

\section{Conflict of Interest}

The authors declare no conflict of interest.

\section{Financial Disclosure}

The authors declare that there is no financial interest in this study.

\section{References}

1. Yen PM. Physiological and molecular basis of thyroid hormone action. Physiol Rev. 2001;81(3):1097-1142.

2. Gamme G, Parrington T, Wiebe E, Ghosh S, Litt B, Williams DC, McMullen TP. The utility of thyroid ultrasonography in the management of thyroid nodules. Can J Surg. 2017;60(2):134-139.

3. Rallison ML, Dobyns BM, Meikle AW, Bishop M, Lyon JL, Stevens W. Natural history of thyroid abnormalities: prevalence, incidence, and regression of thyroid diseases in adolescents and young adults. Am J Med. 1991;91(4):363-370.

4. Gurleyik E, Gurleyik G, Karapolat B, Onsal U. Incidental Papillary Thyroid Microcarcinoma in an Endemic Goiter Area. J Thyroid Res. 2016;2016:1784397.

5. Zimmermann MB. Iodine deficiency. Endocr Rev. 2009;30(4):376-408.

6. Vanderpump MP. The epidemiology of thyroid disease. Br Med Bull. 2011;99:39-51.

7. Vanderpump MPJ. The epidemiology of thyroid diseases. In: Braverman LE, Utiger RD, editors. Werner and Ingbar's The Thyroid: A Fundamental and Clinical Text. 9th edn. Philadelphia: JB Lippincott-Raven 2005; p. 398496.

8. Lamfon HA. Thyroid disorders in Makkah, Saudi Arabia. Ozean J Appl Sci. 2008;1:55-58.

9. Garber JR, Cobin RH, Gharib H, Hennessey JV, Klein I, Mechanick JI, Pessah-Pollack R, et al. Clinical practice guidelines for hypothyroidism in adults: cosponsored by the American Association of Clinical Endocrinologists and the American Thyroid Association. Endocr Pract. 2012;18(6):988-1028.

10. Thyroid Information, American Thyroid Association. https://www.thyroid.org/thyroid-information/.

11. Nix P, Nicolaides A, Coatesworth AP. Thyroid cancer review 1: presentation and investigation of thyroid cancer. Int J Clin Pract. 2005;59(11):1340-1344.

12. DeLellis RA, Williams ED. Pathology of the thyroid and parathyroid. In: DeLellis RA, Lloyd RV, Heitz PU, Eng $\mathrm{C}$ (eds), Pathology and genetics of tumours of endocrine organs, World Health Organization Classification of Tumours, IARC Press, Lyon, 2004; p. 57-66.

13. Ezzat S, Sarti DA, Cain DR, Braunstein GD. Thyroid incidentalomas. Prevalence by palpation and ultrasonography. Arch Intern Med. 1994;154(16):1838-1840.

14. Dean DS, Gharib H. Epidemiology of thyroid nodules. Best Pract Res Clin Endocrinol Metab. 2008;22(6):901911.

15. Usha Menon V, Sundaram KR, Unnikrishnan AG, Jayakumar RV, Nair V, Kumar H. High prevalence of undetected thyroid disorders in an iodine sufficient adult south Indian population. J Indian Med Assoc. 2009;107(2):7277.

16. Boring G, Squires T, Tang T. Epidemiology of cancer. CA Cancer J Clin. 1991;41:19-36.

17. Spitz MR, Sider JG, Katz RL, Pollack ES, Newell GR. Ethnic patterns of thyroid cancer incidence in the United States, 1973-1981. Int J Cancer. 1988;42(4):549-553.

18. Ross DS. Editorial: predicting thyroid malignancy. J Clin Endocrinol Metab. 2006;91(11):4253-4255.

19. Pellegriti G, Frasca F, Regalbuto C, Squatrito S, Vigneri R. Worldwide increasing incidence of thyroid cancer: update on epidemiology and risk factors. J Cancer Epidemiol. 2013;2013:965212.

20. Al Shahrani AS, El-Metwally A, Al-Surimi K, Bin Salih S, Saleh Y, Al-Shehri A, Ali A. The epidemiology of thyroid diseases in the Arab world: A systematic review. J Public Health Epidemiol. 2016;8:17-26.

21. Qari FA. Pattern of thyroid malignancy at a University Hospital in Western Saudi Arabia. Saudi Med J. 2004;25(7):866-870.

22. Abdulmughni YA, Al-Hureibi MA, Al-Hureibi KA, Ghafoor MA, Al-Wadan AH, Al-Hureibi YA. Thyroid cancer in Yemen. Saudi Med J. 2004;25(1):55-59.

23. Larijani B, Aghakhani S, Khajeh-Dini H, Baradar-Jalili R. Clinico-pathological features of thyroid cancer as observed in five referral hospitals in Iran--a review of 1177 cases. Acta Oncol. 2003;42(4):334-337.

24. El-Ghamrawi KA, Khalifa MS. Thyroid cancer in Kuwait: review of 117 cases. Br J Surg. 1979;66(2):139-142.

25. Hussain F, Iqbal S, Mehmood A, Bazarbashi S, ElHassan $\mathrm{T}$, Chaudhri N. Incidence of thyroid cancer in the Kingdom of Saudi Arabia, 2000-2010. Hematol Oncol Stem Cell Ther. 2013;6(2):58-64.

26. Albasri A, Sawaf Z, Hussainy AS, Alhujaily A. Histopathological patterns of thyroid disease in Al-Madinah region of Saudi Arabia. Asian Pac J Cancer Prev. 2014;15(14):5565-5570.

27. Refeidi AA, Al-Shehri GY, Al-Ahmary AM, Tahtouh MI, Alsareii SA, Al-Ghamdi AG, Mahfouz AA, et al. Patterns of thyroid cancer in Southwestern Saudi Arabia. Saudi Med J. 2010;31(11):1238-1241.

28. Kingdom of Saudi Arabia, Ministry of Health, National Cancer Registry. Cancer Incidence Report. 1999-2000. 2004.

29. Parkin DM, Whelan SL, Ferlay J, et al. Cancer incidence in five Continents. Vol. VII. Lyon, IARC : IARC Sci. Publ. No. 143, 1997.

30. Khaliq AA. The Saudi healthcare system: a view from the 
Minaret, World Health \& Population, 13. 2012; p. 52-64.

31. Sebai ZA, Milaat WA, Al-Zulaibani AA. Health care services in saudi arabia: past, present and future. J Family Community Med. 2001;8(3):19-23.

32. Papini E, Guglielmi R, Bianchini A, Crescenzi A, Taccogna S, Nardi F, Panunzi C, et al. Risk of malignancy in nonpalpable thyroid nodules: predictive value of ultrasound and color-Doppler features. J Clin Endocrinol Metab. 2002;87(5):1941-1946.

33. Koike E, Noguchi S, Yamashita H, Murakami T, Ohshima A, Kawamoto H, Yamashita H. Ultrasonographic characteristics of thyroid nodules: prediction of malignancy. Arch Surg. 2001;136(3):334-337.

34. Handa U, Garg S, Mohan H, Nagarkar N. Role of fine needle aspiration cytology in diagnosis and management of thyroid lesions: A study on 434 patients. J Cytol. 2008;25:13-17.

35. Alaamer AS. Radiography education and training in Saudi Arabia. Open J Radiol. 2012;2:134-140.

36. Alsharif W, Davis M, McGee A, Rainford L. An investigation of Saudi Arabian MR radiographers' knowledge and confidence in relation to MR image-quality-related errors. Radiography (Lond). 2017;23(2):e27-e33.

37. Cibas ES, Ali SZ. The Bethesda System For Reporting Thyroid Cytopathology. Am J Clin Pathol. 2009;132(5):658-665.

38. Gharib H, Papini E, Paschke R, Duick DS, Valcavi R, Hegedus L, Vitti P, et al. American Association of Clinical Endocrinologists, Associazione Medici Endocrinologi, and EuropeanThyroid Association Medical Guidelines for Clinical Practice for the Diagnosis and Management of Thyroid Nodules. Endocr Pract. 2010;16(Suppl 1):143.

39. Sengupta S, Tuli IP, Baruah B, Kesari SP, Ilapakurty B, Gupta A. Spectrum of goitrous lesions in patients at a tertiary care center of Sikkim. Sahel Med J. 2014;17:112116.

40. Qureshi IA, Khabaz MN, Baig M, Begum B, Abdelrehaman AS, Hussain MB. Histopathological findings in goiter: A review of 624 thyroidectomies. Neuro Endocrinol Lett. 2015;36(1):48-52.

41. Salama SI, Abdullah LS, al-Qahtani MH, and al-Maghrabi, JA. Histopathological pattern of thyroid lesions in western region of saudi Arabia. New Egypt J Med. 2009;40:580-585.

42. Al-Bouq Y, Fazili FM, Gaffar HA. The current pattern of surgically treated thyroid diseases in the medinah region of Saudi Arabia. JK Pract. 2006;13:9-14.

43. Mansoor R, Rizvi RS, Hida TS, Khan C. Spectrum of thyroid diseases: An experience in a tertiary care and teaching hospital. Ann Pak Ins Med Sci. 2010;6:101-106.

44. Ogbera AO, Kuku SF. Epidemiology of thyroid diseases in Africa. Indian J Endocrinol Metab. 2011;15(Suppl
2):S82-88.

45. Hurtado-Lopez LM, Basurto-Kuba E, Montes de OcaDuran ER, Pulido-Cejudo A, Vazquez-Ortega R, AthieGutierrez C. Prevalence of thyroid nodules in the Valley of Mexico. Cir Cir. 2011;79(2):114-117.

46. Abrari A, Ahmad SS, Bakshi V. Cytology in the otorhinolaryngologist's domain - a study of 150 cases, emphasizing diagnostic utility and pitfalls. Indian J Otolaryngol Head Neck Surg. 2002;54(2):107-110.

47. Musani AM, Khan AF, Ashrafi KS, Jawaid I, Mugeri N, Malik S, et al. Spectrum of thyroid disease presenting in ENT dept. Evaluation by F.N.A.C. Pak J Otolaryngol. 2010;26:74-75.

48. Hashimoto H. Zur Kenntnis der Lymphomatosen Veranderungen der Schilddruse (Struma Lymphomatosa). Arch Klin Chir. 1912;97:S219-S248.

49. Zaletel K, Gaberscek S. Hashimoto's Thyroiditis: From Genes to the Disease. Curr Genomics. 2011;12(8):576588.

50. Hashimoto's Thyroiditis: Information for Patients page. The American Association of Clinical Endocrinologists (AACE) Web site. Available at: http://www.aace.com/ pub/thyroidbrochures/pdfs/Hashimoto.pdf. 2005. Accessed May 25, 2010.

51. Cipolla C, Sandonato L, Graceffa G, Fricano S, Torcivia A, Vieni S, Latteri S, et al. Hashimoto thyroiditis coexistent with papillary thyroid carcinoma. Am Surg. 2005;71(10):874-878.

52. Anil G, Hegde A, Chong FH. Thyroid nodules: risk stratification for malignancy with ultrasound and guided biopsy. Cancer Imaging. 2011;11:209-223.

53. Martin HE, Ellis EB. Biopsy by Needle Puncture and Aspiration. Ann Surg. 1930;92(2):169-181.

54. Cooper DS, Doherty GM, Haugen BR, Kloos RT, Lee SL, Mandel SJ, Mazzaferri EL, et al. Management guidelines for patients with thyroid nodules and differentiated thyroid cancer. Thyroid. 2006;16(2):109-142.

55. Gharib H, Papini E, Valcavi R, Baskin HJ, Crescenzi A, Dottorini ME, Duick DS, et al. American Association of Clinical Endocrinologists and Associazione Medici Endocrinologi medical guidelines for clinical practice for the diagnosis and management of thyroid nodules. Endocr Pract. 2006;12(1):63-102.

56. Barroeta JE, Baloch ZW, Lal P, Pasha TL, Zhang PJ, LiVolsi VA. Diagnostic value of differential expression of CK19, Galectin-3, HBME-1, ERK, RET, and p16 in benign and malignant follicular-derived lesions of the thyroid: an immunohistochemical tissue microarray analysis. Endocr Pathol. 2006;17(3):225-234.

57. Barut F, Onak Kandemir N, Bektas S, Bahadir B, Keser S, Ozdamar SO. Universal markers of thyroid malignancies: galectin-3, HBME-1, and cytokeratin-19. Endocr Pathol. 2010;21(2):80-89. 